\title{
Risk of falling in patients with a recent fracture
} Svenhjalmar van Helden*1, Caroline E Wyers², Pieter C Dagnelie², Martien C van Dongen ${ }^{2}$, Gittie Willems ${ }^{1}$, Peter RG Brink ${ }^{1}$ and Piet P Geusens ${ }^{3,4}$

Address: ${ }^{1}$ Department of General Surgery/traumatology, University Hospital Maastricht, Maastricht, The Netherlands, ${ }^{2}$ Department of Epidemiology, Maastricht University, Maastricht, The Netherlands, ${ }^{3}$ Department of Internal Medicine, University Hospital Maastricht, Maastricht, The Netherlands and ${ }^{4}$ Biomedical Research Institute, Hasselt University, Diepenbeek, Belgium

Email: Svenhjalmar van Helden* - svhl@surgery.azm.nl; Caroline E Wyers - caroline.wyers@gmail.com; Pieter C Dagnelie - Dagnelie@EPID.unimaas.nl; Martien C van Dongen - MCJM.vanDongen@EPID.unimaas.nl; Gittie Willems - BWIL@vea4.azm.nl; Peter RG Brink - P.Brink@surgery.azm.nl; Piet P Geusens - piet.geusens@scarlet.be

* Corresponding author

Published: 28 June 2007

BMC Musculoskeletal Disorders 2007, 8:55 doi:10.1 186/147/-2474-8-55
Received: 4 January 2007

Accepted: 28 June 2007

This article is available from: http://www.biomedcentral.com/I47/-2474/8/55

(C) 2007 van Helden et al; licensee BioMed Central Ltd.

This is an Open Access article distributed under the terms of the Creative Commons Attribution License (http://creativecommons.org/licenses/by/2.0), which permits unrestricted use, distribution, and reproduction in any medium, provided the original work is properly cited.

\begin{abstract}
Background: Patients with a history of a fracture have an increased risk for future fractures, even in short term. The aim of this study was to assess the number of patients with falls and to identify fall risk factors that predict the risk of falling in the first three months after a clinical fracture.
\end{abstract}

Methods: Prospective observational study with 3 months of follow-up in a large European academic and regional hospital. In 277 consenting women and men aged $\geq 50$ years and with no dementia and not receiving treatment for osteoporosis who presented to hospital with a clinical fracture, fall risk factors were assessed according to the guidelines on fall prevention in the Netherlands. Follow-up information on falls and fractures was collected by monthly telephone interview. Incidence of falls and odds ratio's (OR, with $95 \%$ confidence intervals) were calculated.

Results: 512 consecutive patients with a fracture were regarded for analysis, 87 were not eligible for inclusion and 137 patients were excluded. No follow-up data were available for II patients. Therefore full analysis was possible in 277 patients.

A new fall incident was reported by 42 patients ( $15 \%$ ), of whom five had a fracture. Of the 42 fallers, 32 had one new fall and 10 had two or more.

Multivariate analysis in the total group with sex, age, ADL difficulties, urine incontinence and polypharmacy showed that sex and ADL were significant fall risk factors. Women had an OR of 3.02 (95\% Cl I. I3-8.06) and patients with ADL-difficulties had an OR of 2.50 (95\% Cl I.27-4.93).

Multivariate analysis in the female group with age, ADL difficulties, polypharmacy and presence of orthostatic hypotension indicated that polypharmacy was the predominant risk factor (OR 2.5I; $95 \% \mathrm{Cl}$ : 1.19 - 5.28). The incidence of falls was $35 \%$ in women with low ADL score and polypharmacy compared to I5\% in women without these risk factors (OR 3.56: $\mathrm{Cl} 1.47-8.67$ ).

Conclusion: $15 \%$ of patients reported a new fall and 5 patients suffered a new fracture within 3 months. Female sex and low ADL score were the major risk factors and, in addition, polypharmacy in women. 


\section{Background}

A history of fracture indicates a risk for future fractures. The absolute risk for fractures is highest in the first year after a clinical fracture (fracture with symptoms urging the patient to look for medical attention) [1]. Therefore, the prevention of new fractures should be a part of post-fracture treatment. Fall prevention interventions have been shown not only to reduce certain risk factors for falling, but also have successfully reduced falls [2]. No fall prevention intervention study so far has been large enough to determine whether reducing falls will also reduce the number of fractures.

One third of the people aged 65 years and above fall every year and in one to five percent the fall results in a fracture [3-8]. The prevalence of falls increases with age, and more in women than in men. It is expected that the number of persons who fall and the number of fractures will increase due to the sharp rising in the ageing population. Hip fractures, vertebral fractures and wrist fractures are the most common fractures, but most of the other fractures after the age of 50 are also associated with osteoporosis and falls [8-10]. Fractures after menopause and in elderly can have severe consequences in terms of mortality and morbidity, including admission to hospital or to a nursing home and a decrease in quality of life $[6,7,9,11]$.

Previous research identified the following fall risk factors: age of 65 years and above, female sex, mobility problems, previous falls, muscle weakness, visual impairment, disturbances of the equilibrium, low bone mineral density, multi-medication use such as sedatives, previous fractures, low grip strength, low physical activity, impaired activities of daily living, depression, cognitive impairment, use of assistive devices, urinary incontinence, Parkinson's disease, fear of falling, living in a nursing home, diabetes mellitus, high blood pressure, orthostatic hypotension and others [5-9,12,13,10,14-23]. Certain fall risk factors are modifiable to prevent falls, including visual impairment, physical activity, mobility, and muscle strength [13]. The fall risk factors examined in this study are used as predictors of new falls after a recent clinical fracture. To our knowledge there are no previous studies where fall risk factors were analysed in a cohort of fracture patients.

The aim of this study was to assess the number of patients with falls within 3 months after a recent clinical fracture, and to identify fall risk factors that predict the risk of falling within 3 months after a recent clinical fracture.

\section{Methods}

\section{Study design and participants}

In September 2004, based on the guideline of the Dutch Institute for Health Care Improvement (CBO) on oste- oporosis and the guideline on fall prevention, a large European hospital initiated a fracture and osteoporosis outpatient clinic in which fracture patients aged 50 years and above are investigated for osteoporosis $[8,10]$. The aim of the outpatient clinic is to improve the care of patients with a clinical fracture, to diagnose osteoporosis, and to determine fall risk in fracture patients. Patients who present with a fracture either at the emergency department, at the outpatients clinic or who are hospitalized because of a facture were invited to the fracture and osteoporosis outpatient clinic.

For the present study, all patients with a clinical fracture that visited the hospital for fracture treatment between April and September 2005 were invited to participate. During the first consultation, the nurse specialized in osteoporosis and fall risk assessment informed and invited every patient individually. If the patient agreed to participate in the study, an informed consent form was signed and handed over to the osteoporosis nurse. The second consultation was combined with a dual-energy $\mathrm{x}$ ray absorptiometry (DXA) measurement. During the second visit, patients were informed about the results of the DXA scan and anamnesis for fracture and fall risk assessment were performed. Patients were included if they were willing to undergo 1) a fall risk assessment and 2) a bone mineral density (BMD) measurement by DXA. Patients were excluded for the following reasons: not completing one of both assessments (fall risk and DXA), deceased, established dementia written down in medical history, living in another region, having a pathological (non osteoporotic) fracture, no informed consent or no show on DXA appointment. Patients already receiving adequate treatment for osteoporosis were not invited to attend the fracture and osteoporosis clinic where the recruitment for the study occurred. The study was approved by the medical ethical committee of the hospital.

\section{Follow-up and outcome assessment}

Follow-up information on falls and fractures was collected by telephone interview, performed monthly for 3 months after the fracture. This three-month period was chosen to evaluate fall risk in the recovery period of the fracture. The osteoporosis nurse asked whether the patient had a fall, and if so, the number and timing of falls and whether the fall resulted in a fracture.

The primary outcome of this study is the incidence of patients who had a fall within the three months of followup. Falls were defined as unintentional events which result in a person coming to rest on the floor or a lower level $[8,9,22,24]$. People who had fallen were classified as a faller or a recurrent faller. A faller was defined as someone who had fallen at least once within 3 months of fol- 
low-up, and a recurrent faller as someone who had fallen twice or more within 3 months of follow-up.

\section{Measurements of risk factors}

Fall risk was assessed by measuring balance, mobility, lower limb muscle strength, handgrip strength, cognitive status, activities of daily living, visual impairment and general measurement such as blood pressure. These risk factors were chosen based on their description in the Dutch guideline for prevention of falls in the elderly [8].

Balance was evaluated by the Four-Test Balance Scale, in which the patient was asked to perform feet together stand, semi-tandem stand, tandem stand and one leg stand [25]. If the patient was not able to hold at least one of these positions for 10 seconds, this counted as one fall risk.

Mobility was assessed by the Timed Get Up and Go Test, in which the patient is asked to rise from a chair, walk 3 meters, turn, walk back and sit down in the chair. If the patient was not able to perform the test within 12 seconds this was regarded as a reduced mobility and increased fall risk $[26,27]$.

Lower limb muscle strength was measured by the Chair Stand Test. In this test, the patient was asked to rise up and sit down from a chair as quickly as possible five times, while not using their arms if possible. If the patient was not able to complete the test within two minutes this was regarded as a fall risk [28].

Handgrip strength was measured by the Jamar dynamometer (Jamar, Irvington, NY). The patient was asked to squeeze two times on a handgrip strength indicator with both hands separately. For each hand the maximum score (in $\mathrm{kg}$ ) was added up. If people squeezed with only one hand, the score of the other hand was replaced by the mean of the group that squeezed with both hands taking sex and dominant hand into account. For women, the cutoff point was $<30 \mathrm{~kg}$, for men the cut-off point was $<50$ $\mathrm{kg}[29]$.

The Abbreviated Mental Test, a questionnaire to test the cognitive status, was used to assess if patients were cognitive impaired. The cut-off point of this test is 8 (range: $0-$ $10)$, with a score less than 8 suggesting abnormal cognitive functioning [30,31].

The Groningen Activity Restriction Scale (GARS) was used to test disability in activities of daily living (ADL) [32]. Patients were asked to answer the questions regarding their abilities just before the fracture. The patient was considered as having a fall risk if he or she had difficulties with a least two out of the three following questions of
GARS: a) Can you, fully independently, go up and down the stairs; b) Can you, fully independently, walk outdoors (if necessary with a cane); and c) Can you, fully independently, take care of your feet and toenails? Visual impairment was measured by the Snellen eye chart. Patients viewed the eye chart at a distance of 3 meters. If the visual acuity was less than 0.4 , the patient was regarded as visually impaired and having a fall risk [33,34].

Blood pressure was measured to determine if orthostatic hypotension was present [35]. It was measured both in lying and standing position (after one minute). Further, patients were asked for previous falls in the past 12 months, the ability to keep their balance, problems with walking, difficulties with rising from a chair, difficulties with dressing and undressing, the use of psychofarmaca, polypharmacy (taking 5 or more pills per day), osteoarthritis (patients were asked for previous medical attention for arthrosis of especially the joint in the lower limb), urinary incontinence (patient was asked for involuntary loss of urine), difficulties with reading the newspaper, and depression.

\section{Statistical analysis}

Statistical analyses were performed using SPSS for Windows version 12.0.1. Individuals without falls were compared with those with falls. First, univariate logistic regression models were fitted with all individual fall risk factors for the total group and women. If a risk factor had an Odds Ratio $(\mathrm{OR}) \geq 2$.0 it was retained for subsequent multivariate analysis.

The logistic regression analysis was fitted by the "Forward Likelihood Ratio" method. To identify the relationship between the fall risk factors and falling, OR's and 95\% confidence intervals were calculated. Interaction was tested for all significant variables resulting from the univariate analysis.

\section{Results}

During an inclusion period of 6 months, 512 patients over the age of 50 with a clinical fracture visited the emergency department or the outpatient clinic (Figure 1). Of those patients, 87 were not eligible for inclusion. Of the resulting 425 patients who where eligible for inclusion, 137 patients were excluded for various reasons. No follow-up data were available for 11 patients. As a result, 277 patients were included with a total of 286 clinical fractures at baseline (inclusion rate $65.2 \%$ of all eligible patients).

A fall from maximum standing height as the cause of the fracture was reported by 246 patients $(88.8 \%)$.

In this study the majority of patients were women $(72.2 \%)$. 


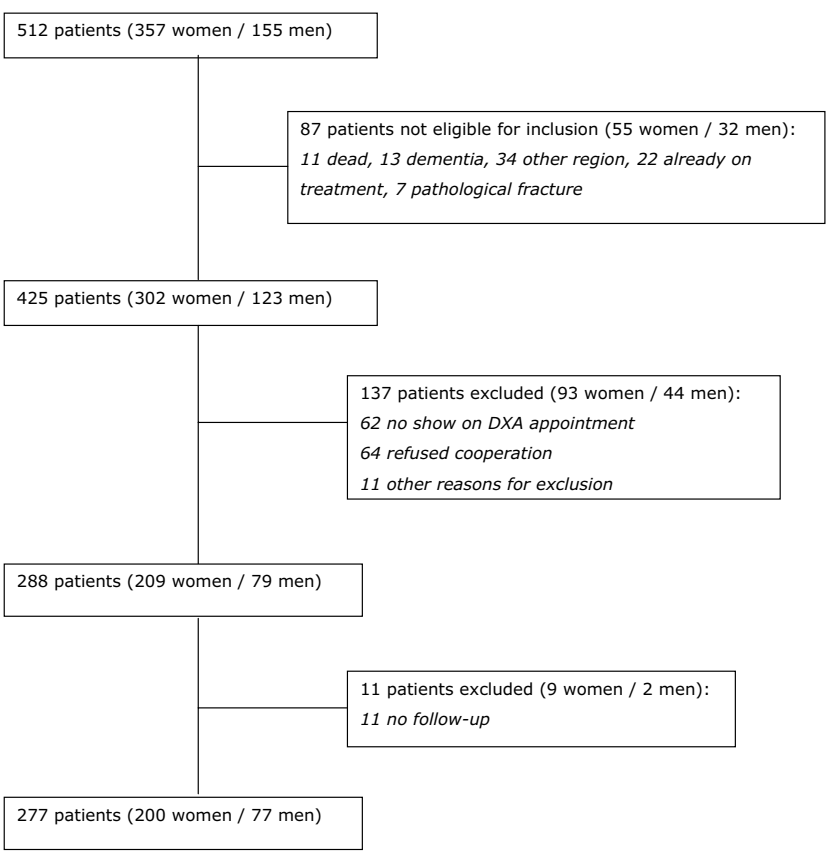

Figure I

Flowchart with inclusion and exclusion of study participants.

A fall within 3 months after a recent clinical fracture was reported by 42 of the patients (15.2\%); the number of women with a fall was higher than the number of men (respectively 37 [18.5\%] and 5 [6.5\%]; $\mathrm{p}=0.013$ ). Of the 42 fallers, 10 were recurrent fallers. The fall rate was 1.5 falls/patient year. In 5 patients a fall resulted in a fracture. Mean age of female fallers was 69.9 years (range: $51-86$ ), and 66.6 years in male fallers (range: $51-78)(\mathrm{p}=0.069)$. All fallers reported that their baseline clinical fracture was the result of a fall from maximum standing height (Table 1 ). One in two fallers had difficulties with ADL before the clinical fracture, compared with one in four of the patients who had no falls during the follow-up $(p=0.003)$. The other characteristics were not significantly different between fallers and non-fallers (Table 1). At least one fall risk factor was present in $84 \%$ of the patients, $76(27 \%)$ had one fall risk factors, 62 (22\%) had two, 47 (17\%) three, and $49(18 \%)$ had four or more fall risk factors (table 2).

Univariate analysis was carried out for 15 fall risk factors (Table 2). Significant fall risk factors for the total population were sex (OR 3.27/women vs. men; 95\% CI 1.238.66 ), age (OR $3.55 / 80$ + vs. 50-59 years; 95\% CI 1.309.65), ADL-problems vs. no ADL problems (OR 2.67; $95 \%$ CI $1.37-5.22$ ), and polypharmacy vs. no polyphar- macy (use of $\geq 5$ pills per day) (OR 2.58; 95\% CI $1.30-$ 5.10). In women, ADL difficulties (OR 2.20; 95\% CI 1.07-4.56) and polypharmacy (OR 2.51; 95\% CI 1.195.28 ) were significant fall risk factors.

Multivariate analysis in the total group with sex, age, ADL difficulties, urine incontinence and polypharmacy showed that sex and ADL were significant fall risk factors. Women had an OR of 3.02 (95\% CI 1.13-8.06) and patients with ADL-difficulties had an OR of 2.50 (95\% CI 1.27-4.93).

Multivariate analysis in the female group with age, ADL difficulties, polypharmacy and presence of orthostatic hypotension indicated that polypharmacy was the predominant risk factor (OR 2.51; 95\% CI: 1.19 - 5.28). The incidence of falls was 35\% in women with polypharmacy and low ADL score. This risk of falls was three times higher than in women without polypharmacy and with normal ADL score. (OR 3.56; 95\% CI 1.47-8.67).

\section{Discussion}

In this study of people over 50 presenting with a fracture, who were not already on osteoporosis treatment, who are not demented and who were able to give informed consent, the incidence of patients with a fall within three months after a clinical fracture was $18.5 \%$ in women and $6.5 \%$ in men. In $11.9 \%$ the fall resulted in a new fracture.

The predominant fall risk factors that predicted a new fall were sex and difficulties in ADL in the total group. In line with other studies, women more often experienced a new fall compared to men [3-8]. Nearly one in three women with polypharmacy as a risk factor had a new fall, compared with one in ten women without this risk factor. The sample was too small to detect differences in fracture.

This study has several limitations. The male group was to small for separate analysis.

The information of the main outcome variable, i.e. falls during follow-up, relied on patients recall of falls, so the possibility of incomplete or biased reports of falls cannot be excluded.

The sample may not be completely typical in view of the various exclusion criteria. Only significant risk factors chosen to measure were described, which by definition can not be exhaustive and some of these assessments were not of the kind that could be carried out within routine clinical practice, but only in a research context.

The follow-up period of three months was short but chosen to evaluate fall risk in the time patients were recovering from their fracture. 
Table I: Characteristics of Study Population

\begin{tabular}{|c|c|c|c|c|c|c|c|}
\hline \multirow[t]{2}{*}{ Characteristic } & \multicolumn{2}{|c|}{ Total group $(n=277)$} & \multicolumn{2}{|l|}{ Fallers $(n=42)$} & \multicolumn{2}{|c|}{ Non fallers $(n=235)$} & \multirow[t]{2}{*}{ p-value } \\
\hline & $\%$ & $\mathrm{n}$ & $\%$ & $\mathrm{n}$ & $\%$ & $\mathrm{n}$ & \\
\hline Sex (female) & 72 & 200 & 88 & 37 & 69 & 163 & $0.013^{*}$ \\
\hline Age, mean (range) years & $67.1(50-91) \dagger$ & & $69.9(5 \mathrm{I}-86)^{\dagger}$ & & $66.6(50-91)^{\dagger}$ & & 0.069 \\
\hline Living at home & 93 & 254 & 91 & 38 & 94 & 216 & 0.478 \\
\hline Low energy trauma & 89 & 246 & 100 & 42 & 87 & 204 & $0.012^{*}$ \\
\hline \multicolumn{8}{|l|}{ Bone Mineral Density $\S$} \\
\hline Normal (Tscore $>-1)$ & 24 & 61 & 19 & 7 & 25 & 54 & 0.438 \\
\hline Osteopenia (Tscore $\leq-\mathrm{I}$ and $>-2.5)$ & 47 & 119 & 47 & 17 & 47 & 102 & 0.945 \\
\hline Osteoporosis (Tscore $\leq-2.5$ ) & 29 & 72 & 33 & 12 & 28 & 60 & 0.323 \\
\hline Weight, mean (range) kg & $71.8(40-120)^{\dagger}$ & & $71.9(45-115)^{\dagger}$ & & $71.8(40-120)^{\dagger}$ & & 0.945 \\
\hline \multicolumn{8}{|l|}{ Fracture type } \\
\hline Upper extremity & 43 & 119 & 36 & 15 & 44 & 104 & 0.430 \\
\hline Lower extremity & 48 & 134 & 57 & 24 & 47 & 110 & 0.305 \\
\hline Trunk & 5 & 15 & 5 & 2 & 6 & 13 & 0.922 \\
\hline Multiple fractures & 3 & 9 & 2 & 1 & 3 & 8 & 0.899 \\
\hline Diabetes & 17 & 47 & 24 & 10 & 16 & 37 & 0.200 \\
\hline Orthostatic hypotension $* *$ & 12 & 33 & 19 & 8 & 11 & 25 & 0.235 \\
\hline \multicolumn{8}{|l|}{ Medication } \\
\hline Antihypertensive & 32 & 89 & 41 & 17 & 31 & 72 & 0.337 \\
\hline Benzodiazepines & 9 & 26 & 14 & 6 & 9 & 20 & 0.473 \\
\hline Antidepressive & 9 & 26 & 12 & 5 & 9 & 21 & 0.750 \\
\hline Anti-rheumatics & 5 & 13 & 7 & 3 & 4 & 10 & 0.649 \\
\hline \multicolumn{8}{|l|}{ Fall risk factors } \\
\hline Mobility (TGUGT) $\ddagger$ & 59 & 164 & 71 & 30 & 57 & 134 & 0.080 \\
\hline$\geq 2$ falls in previous year $\ddagger$ & 30 & 84 & 43 & 18 & 28 & 66 & 0.055 \\
\hline Use of benzodiazepines $\ddagger$ & 10 & 28 & 10 & 4 & 10 & 24 & 0.891 \\
\hline ADL difficulties $\ddagger$ & 31 & 85 & 50 & 21 & 27 & 64 & $0.003^{*}$ \\
\hline Osteoarthritis $\ddagger$ & 34 & 95 & 31 & 13 & 35 & 82 & 0.620 \\
\hline Visual impairment $\ddagger$ & 18 & 50 & 24 & 10 & 17 & 40 & 0.292 \\
\hline Urinary incontinence $\ddagger$ & 18 & 50 & 29 & 12 & 16 & 38 & 0.054 \\
\hline Parkinson's disease $\ddagger$ & 1 & 2 & 0 & 0 & 1 & 2 & 0.548 \\
\hline \multicolumn{8}{|c|}{$\begin{array}{l}\text { * significant: } p<.05 \\
\S \text { results of } 252 \text { subjects } \\
\text { ** (20 mmHg drop in systolic BP and/or } 10 \mathrm{mmHg} \text { drop in diastolic BP I minute after standing) } \\
\text { † Mean (range) } \\
\text { fFall risk factor according to the Dutch guideline on fall prevention (TGUGT: Timed Get Up and Go Test: cut off at I2 seconds; ADL difficulties: fall risk if he or she had } \\
\text { difficulties with a least two out of the three following questions of Gronigen Activity Restriction Scale: a) Can you, fully independently, go up and down the stairs; b) Can you, } \\
\text { fully independently, walk outdoors (if necessary with a cane); and c) Can you, fully independently, take care of your feet and toenails?; Visual impaiment: cut off at visual acuity } \\
\text { less than 0.4; }\end{array}$} \\
\hline
\end{tabular}

Based on the results of our study, a health care provider can identify patients with the highest risk of falls after a fracture examining ADL in all patients, and polypharmacy in women.

Future studies should be large enough to include sufficient numbers of men and perform subgroup analysis on different ages. Eventually a very large cohort analysis with fracture risk as endpoint would be most interesting.

\section{Conclusion}

Patients with a recent clinical fracture have a high risk for new falls. In a group of 277 patients, 15\% reported a new fall and 5 patients suffered a new fracture within 3 months. Female sex and low ADL score were the major risk factors and, in addition, polypharmacy in women.

\section{Competing interests}

$\mathrm{SH}$ is member of an advisory board of Merck Sharp Dohme. SH and PG received an unrestricted grant for research by MSD (not current study).

All other auhors have no conflict of interest

\section{Authors' contributions}

SH coordinated study concept and design, performed acquisition of data together with analysis and interpretation and prepared the final manuscript. CW performed 
Table 2: Fall risk factors predicting the risk of falling within 3 months after a fracture: univariate analysis

\begin{tabular}{|c|c|c|c|c|}
\hline & \multicolumn{2}{|r|}{ Total } & \multicolumn{2}{|r|}{ Women } \\
\hline & \multicolumn{2}{|r|}{$(n=277)$} & \multicolumn{2}{|r|}{$(n=200)$} \\
\hline & OR* & $95 \% \mathrm{Cl}$ & OR* & $95 \% \mathrm{Cl}$ \\
\hline Sex (female) & 3.27 & $1.23-8.66$ & - & - \\
\hline Age $(80+$ yrs vs. $50-59)$ & 3.55 & $1.30-9.65$ & 2.88 & $0.99-8.40$ \\
\hline Mobility (TGUGT)†‡ & 1.88 & $0.92-3.86$ & 1.75 & $0.79-3.85$ \\
\hline$\geq 2$ falls in previous yeart & 1.92 & $0.98-3.77$ & 1.76 & $0.86-3.64$ \\
\hline Use of benzodiazepines ${ }^{\dagger}$ & 0.93 & $0.30-2.82$ & 1.11 & $0.35-3.55$ \\
\hline ADL difficulties $\$ \neq$ & 2.67 & $1.37-5.22$ & 2.20 & $1.07-4.56$ \\
\hline Arthrosis ${ }^{\dagger}$ & 0.84 & $0.41-1.70$ & 0.61 & $0.28-1.31$ \\
\hline Visual impairment ${ }^{\dagger}$ & 1.52 & $0.69-3.35$ & 1.03 & $0.42-2.58$ \\
\hline Urinary incontinence ${ }^{\dagger}$ & 2.07 & $0.98-4.41$ & 1.49 & $0.67-3.31$ \\
\hline Polypharmacy ( $\geq 5$ pills/day) & 2.58 & $1.30-5.10$ & 2.51 & $1.19-5.28$ \\
\hline Orthostatic hypotension $\ddagger$ & 1.98 & $0.82-4.74$ & 2.22 & $0.88-5.60$ \\
\hline Cognitive impairment ${ }^{\ddagger}$ & 1.67 & $0.76-3.69$ & 1.33 & $0.55-3.21$ \\
\hline Handgrip strength $\ddagger$ & 1.95 & $0.94-4.05$ & 1.46 & $0.64-3.31$ \\
\hline FTBS feet together $\ddagger$ & 1.43 & $0.7 I-2.89$ & 1.48 & $0.68-3.21$ \\
\hline FTBS semi-tandem stand $\ddagger$ & 1.55 & $0.77-3.11$ & 1.61 & $0.75-3.45$ \\
\hline FTBS tandem stand $¥$ & 1.36 & $0.70-2.64$ & 1.39 & $0.68-2.85$ \\
\hline FTBS one leg stand $\ddagger$ & 1.83 & $0.91-3.70$ & 1.79 & $0.8 I-3.95$ \\
\hline Chair stand test $\ddagger$ & 1.66 & $0.85-3.26$ & 1.77 & $0.85-3.68$ \\
\hline
\end{tabular}

*Values presented are crude OR's, significant OR's are printed in bold.

tFall risk factors according to the Dutch guideline on fall prevention.

$\ddagger$ Abbreviations and cut off values: Timed Get Up and Go Test (TGUGT) cut off at 12 seconds. Activities of Daily Living (ADL) difficulties: fall risk if he or she had difficulties

with a least two out of the three following questions of Groningen Activity Restriction Scale: a) Can you, fully independently, go up and down the stairs; b) Can you, fully

independently, walk outdoors (if necessary with a cane); and c) Can you, fully independently, take care of your feet and toenails?

Visual impairment: cut off at visual acuity less than 0.4 .

Orthostatic hypotension: $20 \mathrm{mmHg}$ drop in systolic BP and/or $10 \mathrm{mmHg}$ drop in diastolic BP I minute after standing.

Cognitive impairment : Abbreviated Mental Test score $\leq 8$.

Handgrip strength : For women, the cut-off point was $<30 \mathrm{~kg}$, for men the cut-off point was $<50 \mathrm{~kg}$.

Four Test Balance Scale (FTBS): If the patient was not able to hold at least one of these positions for I0 seconds, this counted as one fall risk.

Chair stand test: If the patient was not able to complete the test within two minutes this was regarded as a fall risk.

analysis and interpretation of data and took part in manuscript preparation. PD took part in analysis and interpretation of data and preparation of the manuscript. MD performed analysis and interpretation of data together with preparation of the manuscript. GW did acquisition of subjects and data. PB took part in preparation of the final manuscript. PG was involved in study concept and design, analysis and interpretation of data and preparation of the final manuscript. All authors read and approved the final manuscript.

\section{Acknowledgements}

The authors like to thank Rene ten Broeke MD from the department of orthopaedic surgery for contributing cases.

\section{References}

I. van Helden S, Cals J, Kessels F, Brink P, Dinant GJ, Geusens P: Risk of new clinical fractures within 2 years following a fracture. Osteoporos Int 2006, I 7(3):348-354.

2. Gillespie LD, Gillespie WJ, Robertson MC, Lamb SE, Cumming RG, Rowe $\mathrm{BH}$ : Interventions for preventing falls in elderly people. Cochrane Database Syst Rev 2003:CD000340.

3. Nevitt MC, Cummings SR, Kidd S, Black D: Risk factors for recurrent nonsyncopal falls. A prospective study. Jama 1989, 26 I ( I 8):2663-2668.
4. Tinetti ME, Speechley M, Ginter SF: Risk factors for falls among elderly persons living in the community. N Engl J Med 1988, 319(26): I70I-I707.

5. Tromp AM, Smit JH, Deeg DJ, Bouter LM, Lips P: Predictors for falls and fractures in the Longitudinal Aging Study Amsterdam. J Bone Miner Res 1998, I3(12):1932-1939.

6. Bloem BR, Boers I, Cramer M, Westendorp RG, Gerschlager W: Falls in the elderly. I. Identification of risk factors. Wien Klin Wochenschr 200I, I I 3( I 0):352-362.

7. Schwartz AV, Villa ML, Prill M, Kelsey JA, Galinus JA, Delay RR, Nevitt MC, Bloch DA, Marcus R, Kelsey J: Falls in older Mexican-American women. J Am Geriatr Soc 1999, 47(I I): I37I-I 378.

8. CBO kvdg: Preventie van valincidenten bij ouderen. 2004 [http://www.cbo.nl/product/richtliinen/folder20021023121843/valrichtlijn2004.pdf/view]. accessed june 5, 2006.

9. Masud T, Morris RO: Epidemiology of falls. Age and Ageing 200I, 30(4):3-8.

10. СBO : Osteoporose. Tweede herziene richtlijn 2002. [http/ www.cbo.nl/product/richtliinen/folder20021023121843/oste oporose.pdf/view]. Utrecht , Kwaliteitsinstituut voor de Gezondheidszorg CBO accessed august 17, 2005

II. Close JCT, Lord SL, Menz HB, Sherrington C: What is the role of falls? Best Practice \& Research Clinical Rheumatology 2005, 19(6):913-935.

12. Prevention and management of Osteoporosis. Geneva World Health Organization; 2003.

13. Shaw FE, Bond J, Richardson DA, Dawson P, Steen IN, McKeith IG, Kenny RA: Multifactorial intervention after a fall in older people with cognitive impairment and dementia presenting to the accident and emergency department: randomised controlled trial. Bmj 2003, 326(7380):73. 
14. Pils K, Neumann F, Meisner W, Schano W, Vavrovsky G, Van der Cammen TJM: Predictors of falls in elderly people during rehabilitation after hip fracture - who is at risk of a second one? Zeitschrift für Gerontologie und Geriatrie 2003, 36(I): 16-22.

15. Wei TS, Hu CH, Wang SH, Hwang Departments of KL: Fall Characterictics, Functional Mobility and Bone Mineral Density as Risk Factors of Hip Fracture in the Community-Dwelling Ambulatory Elderly. Osteoporosis International 2001, I 2(1 2): 1050- 055.

16. Albrand G, Munoz F, Sornay-Rendu E, DuBoeuf F, Delmas PD: Independent predictors of all osteoporosis-related fractures in healthy postmenopausal women: The OFELY Study. Bone 2003, 32(I):78-85.

17. Solomon DH, Finkelstein JS, Polinski JM, Arnold M, Licari A, Cabral D, Canning C, Avorn J, Katz JN: A randomized controlled trial of mailed osteoporosis education to older adults. Osteoporos Int 2006, I7(5):760-767.

18. Close JCT, Hooper R, Glucksman E, Jackson SHD, Swift CG: Predictors of falls in a high risk population: results from the prevention of falls in the elderly trial (PROFET). Emerg Med J 2003 20(5):42I-425.

19. Francis RM: Falls and fractures. Age and Ageing 200I, 30(4):25-29.

20. Stalenhoef PA, Diederiks JP, Knottnerus JA, de Witte LP, Crebolder HF: The construction of a patient record-based risk model for recurrent falls among elderly people living in the community. Fam Pract 2000, 17(6):490-496.

21. Stalenhoef PA, Diederiks JP, Knottnerus JA, Kester AD, Crebolder HF: A risk model for the prediction of recurrent falls in community-dwelling elderly: a prospective cohort study. J Clin Epidemiol 2002, 55(II): 1088-1094.

22. Geusens $\mathrm{P}$, Milisen K, Dejaeger E, Boonen S: Falls and fractures in postmenopausal women: a review. J Br Menopause Soc 2003, 9(3): $101-106$.

23. Scott V, Votova K, Scanlan A, Close J: Multifactorial and functional mobility assessment tools for fall risk among older adults in community, home-support, long-term and acute care settings. Age Ageing 2007, 36(2):130-139.

24. Kenny RA, Rubenstein LZ, Martin FC, Tinetti ME: Guideline for the Prevention of Falls in Older Persons. Journal of the American Geriatrics Society 200I, 49(5):664-672.

25. Rossiter-Fornoff JE, Wolf SL, Wolfson LI, Buchner DM: A cross-sectional validation study of the FICSIT common data base static balance measures. Frailty and Injuries: Cooperative Studies of Intervention Techniques. J Gerontol A Biol Sci Med Sci 1995, 50(6):M29I-7.

26. Podsiadlo D, Richardson S: The timed "Up \& Go": a test of basic functional mobility for frail elderly persons. J Am Geriatr Soc 199|, 39(2): | 142-148.

27. Bischoff HA, Stahelin HB, Monsch AU, Iversen MD, Weyh A, von Dechend M, Akos R, Conzelmann M, Dick W, Theiler R: Identifying a cut-off point for normal mobility: a comparison of the timed 'up and go' test in community-dwelling and institutionalised elderly women. Age and Ageing 2003, 32(3):3I5-32I.

28. Guralnik JM, Simonsick EM, Ferrucci L, Glynn RJ, Berkman LF, Blazer DG, Scherr PA, Wallace RB: A short physical performance battery assessing lower extremity function: association with self-reported disability and prediction of mortality and nursing home admission. J Gerontol 1994, 49(2):M85-94.

29. Tromp AM, Pluijm SM, Smit JH, Deeg DJ, Bouter LM, Lips P: Fall-risk screening test: a prospective study on predictors for falls in community-dwelling elderly. J Clin Epidemiol 2001, 54(8):837-844.

30. Hodkinson HM: Evaluation of a mental test score for assessment of mental impairment in the elderly. Age Ageing 1972, I(4):233-238

31. Jitapunkul S, Pillay I, Ebrahim S: The abbreviated mental test: its use and validity. Age Ageing 1991, 20(5):332-336.

32. Kempen GI, Miedema I, Ormel J, Molenaar W: The assessment of disability with the Groningen Activity Restriction Scale. Conceptual framework and psychometric properties. Soc Sci Med 1996, 43(II): 160I-1610.

33. Lord SR, Dayhew J: Visual risk factors for falls in older people. J Am Geriatr Soc 200I, 49(5):508-5I5.

34. Sherman FT: Functional assessment. Easy-to-use screening tools speed initial office work-up. Geriatrics 200I, 56(8):36-40; quiz 43.
35. Carey BJ, Potter JF: Cardiovascular causes of falls. Age Ageing 200I, 30 Suppl 4:19-24.

\section{Pre-publication history}

The pre-publication history for this paper can be accessed here:

http://www.biomedcentral.com/1471-2474/8/55/prepub
Publish with Bio Med Central and every scientist can read your work free of charge

"BioMed Central will be the most significant development for disseminating the results of biomedical research in our lifetime. "

Sir Paul Nurse, Cancer Research UK

Your research papers will be:

- available free of charge to the entire biomedical community

- peer reviewed and published immediately upon acceptance

- cited in PubMed and archived on PubMed Central

- yours - you keep the copyright
BioMedcentral 